\title{
The family and the dominant technocratic paradigm: challenges in the digital culture
}

\section{Amoris Laetitia, culture and technology}

Like other magisterial documents following in the footsteps of the Second Vatican Council, Pope Francis' Post-synodal apostolic exhortation Amoris Laetitia: on love in the family, not only seeks to respond to "the signs of the times," " but considers culture to be the environment in which families

* Dr. Nadia Delicata is a senior lecturer in fundamental moral theology and Christianity and culture at the Faculty of Theology of the University of Malta. Her primary area of research is on the interface of Christian living in the digital age, in particular through a "media ecology" hermeneutic and the work of the Toronto School of Communications. Dr. Delicata was a research fellow of the "McLuhan Programme in Culture and Technology" and serves on the organizing committee of "Theocom," the yearly ecumenical gathering of theologians to reflect on theology, communications and digital culture, previously sponsored by the Pontifical Council for Social Communications. She has published various articles on the topic of Christianity in the digital age and is a speaker at international conferences on this emerging theme. She is a member of the Professional Ethics Programme of the University of Malta, and a regular member of the Maltese Archdiocese's think tank that drafts position papers on legislation and socio-cultural themes in Malta. She serves on the Maltese Inter-Diocesan Theological Commission and the Board of Maltese Archdiocese's Pastoral Formation Institute.

1 Gaudium et Spes 4. 
thrive and, more often than not, are profoundly challenged. Pope Francis assumes the pastoral wisdom that has become a sine qua non of the postconciliar Church, that "cultures are in fact quite diverse and every general principle... needs to be inculturated, if it is to be respected and applied."2 More significantly, in the second chapter of the exhortation that is dedicated entirely to reflecting upon "the experiences and challenges of families," the pope stresses the necessity of studying culture to understand the very difficulties that families are confronted by: "Faithful to Christ's teaching we look to the reality of the family today in all its complexity, with both its lights and shadows... Anthropological and cultural changes in our times influence all aspects of life and call for an analytic and diversified approach."3

What are these "anthropological and cultural changes" that threaten family well-being today? The second chapter of Amoris Laetitia offers a detailed analysis of diverse social conditions, political realities and ideological assumptions that affect family life around the globe. Some concerns are specific to local dioceses. The majority, however - like economic hardship related to unemployment, single parenthood or migration; unjust legislation like abortion or sterilization programmes; or psychological problems like addictions of all kinds - are increasingly widespread. They might take different permutations in different countries. But the experience of suffering and the trial they pose to families transcend all boundaries.

Among these irrefutable challenges of poverty, political injustice and personal hardship, I suggest that new culture-bound, but also trans-cultural widely deemed 'acceptable' lifestyles, mindsets and assumptions about the "good life" should also raise concern, even if they might appear as relatively innocuous or indeed, be branded as "progress."

For instance, the pope mentions: "a 'culture of the ephemeral." Here I think, for example, of the speed with which people move from one affective relationship to another. They believe, along the lines of social networks, that love can be connected or disconnected at the whim of the consumer, and the relationship quickly 'blocked." 4

2 Amoris Laetitia 3 quoting Gaudium et Spes 44.

3 Amoris Laetitia 32 quoting Relatio Synodi (2014) 5, emphasis added.

4 Amoris Laetitia 39. 
Pope Francis is also concerned about how "we treat affective relationships the way we treat material objects and the environment: everything is disposable; everyone uses and throws away, takes and breaks, exploits and squeezes to the last drop. Then, goodbye..."

Similarly, he adds: "the decline in population, due to a mentality against having children and promoted by the world politics of reproductive health, creates not only a situation in which the relationship between generations is no longer ensured but also the danger that, over time, this decline will lead to economic impoverishment and a loss of hope in the future. The development of biotechnology has also had a major impact on the birth rate."

Notwithstanding their apparent differences, what these new attitudes seem to have in common is some relation, which needs to be studied and understood, to new technological realities. As the Pontiff notes, the 'culture of the ephemeral' appears to replicate the patterns of interaction on online social networks. A tendency to objectifying the other echoes the consumerist ethos, itself grounded in mechanical means of production and an instrumentalist mind-set. While in the case of biotechnology, the pope is clearer still: biotechnology, and not just specific products, techniques or pharmaceuticals, has had an impact on human population cycles. What the pope seems to be implying is that technology is not just something that we use. On a more fundamental level, technology changes us as its users, by silently instructing us in new habits of experiencing, reasoning and acting. Just as pondering a book implicitly trains the reader to be focused and persistent not just when struggling with a text, but as an appropriated lifestyle attitude, so browsing online seems to be tacitly shaping us to surface gaze, judge instantaneously based on immediate (hopefully accurate) impressions, and weave meaning through individually appropriated (or created) narratives. Undoubtedly, in this new environment, new skills and habits are being gained or retrieved that tend to enhance or replace previously held assumptions and lifestyle stances. What is more, insofar as human beings naturally belong to social groupings - the most basic of which is the family - the subtle effects of technology necessarily become systemic: they literally augment to the point of weaving the very fabric of culture.

5 Amoris Laetitia 39.

6 Amoris Laetitia 18. 
This interest in technological phenomena and their effects on family life is also evident in Amoris Laetitia's seventh chapter, "Towards a better education of children." Here, Pope Francis reflects on a dynamic that is extremely typical of contemporary family life. He also reiterates key insights from recent World Communications Day Messages ${ }^{7}$ where new communication technologies are presented as phenomena that recreate how we live, interact with one another and urge us to reconsider what is culturally normative. In other words, new communication technologies are creating a new culture embedded in a digitally-augmented environment. Yet, these new patterns of relationality are not always enriching the common good, nor do they come without personal and communal risks. For example: "The educational process that occurs between parents and children can be helped or hindered by the increasing sophistication of the communications and entertainment media. When well used, these media can be helpful for connecting family members who live apart from one another. [...] Still, it is clear that these media cannot replace the need for more personal and direct dialogue, which requires physical presence or at least hearing the voice of the other person. We know that sometimes they can keep people apart rather than together, as when at dinnertime everyone is surfing on a mobile phone, or when one spouse falls asleep waiting for the other who spends hours playing with an electronic device. This is also something that families have to discuss and resolve in ways which encourage interaction without imposing unrealistic prohibitions. In any event, we cannot ignore the risks that these new forms of communication pose for children and adolescents; at times they can foster apathy and disconnect from the real world. This 'technological disconnect' exposes them more easily to manipulation by those who would invade their private space with selfish interests."

In this paper, I will explore how these seemingly disconnected references to technology in Amoris Laetitia are more important to the future of the

7 The most important on this theme are the messages penned by Pope Benedict XVI for the $43^{\text {rd }}$ World Communications Day New technologies, new relationships. Promoting a culture of respect, dialogue and friendship (2009), the $45^{\text {th }}$ World Communications Day Truth, proclamation and authenticity of life in the digital age (2011) and the $47^{\text {th }}$ World Communications Day Social networks: portals of truth and faith; new spaces for evangelization (2013), and the Message written by Pope Francis for the $48^{\text {th }}$ World Communications Day Communication at the service of an authentic culture of encounter (2014).

8 Amoris Laetitia 278, emphasis added. 
family and its pastoral care than might appear at face value. I will suggest that if we apply the teaching at the heart of Pope Francis' encyclical Laudato Si: on care for our common home, we can shed much light on a foundational bias, indeed a manifestation of a deep-seated structural sin in our times, that threatens to not just "change," but dismember the family as fundamental relational and formative human experience. A study of how technology shapes culture and our self-understanding as human beings must take centre stage in all reflection on the family and, in particular, on education, for the flourishing of society's most vulnerable members and its very future wellbeing.

I will proceed first, by analysing Pope Francis' presentation of the "dominant technocratic paradigm" in Laudato Si and argue how it becomes a manifestation of sinfulness precisely through "anthropological and cultural changes" that distort an "integral ecology."10 Even if technologizing is natural to the human and indeed, necessary to exercise well our participation in God's creative action in the world, any technological "extension"11 of human living requires a "measure" to assist our discernment of whether it is enhancing human flourishing or thwarting it. As I will present next, a suitable "measure" is obtainable through the tradition of natural law reasoning that gives us criteria to evaluate whether our artisanry is true 'technology' assisting "integral development" (that is, an exemplar of the reasonability of techne), or 'technocracy', imprisoning us in the biased worldview of our sinfulness.

In the following sections I will focus on the effects on the family of particular technologies that are shaping our contemporary milieu by "changing" the expression of our natural inclinations as outlined by St. Thomas Aquinas' classic presentation of natural law. I will focus in particular on technologies that affect family living directly: communication technologies that shape how we relate to one another, reproductive technologies that change the very configuration of being a family, and how both, through being expressions of an "information" mind-set, reposit the question of our creatureliness in relation to the Creator.

9 Laudato Sì 101.

10 Laudato Si 62.

11 The term "extension" is taken from the title of Marshall McLuhan's classic, Understanding media: the extensions of man, Toronto 1964. 
In conclusion, in line with the pedagogical emphasis of Amoris Laetitia, I will suggest how a pivotal challenge for the Church today is inviting conversion from the technocratic paradigm, without which we cannot really be freed to pursue our flourishing through "the Gospel of the family"12

\section{The "dominant technocratic paradigm" in Laudato Sì}

Laudato Si can be interpreted as written in a chiastic structure, where chapters not only echo each other, but reveal their core meaning in the very heart of the document. Chapter one ponders the scriptural foundation of the theological doctrine of creation, while the concluding sixth chapter stresses the necessity of an ecological conversion, education and spirituality that makes manifest God's plan for the created realm. Likewise, while chapter two offers a realistic picture of the ecological crisis, chapter five suggests concrete lines of action to juxtapose it. In these first two sets of chapters, that seem to guide our reflection through the traditional exitus-reditus scheme, we see how, if our senses must first - and ultimately - turn to God to receive and appropriate His revelation (chapters one and six), they must also be attentive to concrete reality. Thus, in chapters two and five, the pope invites us to turn our gaze to the world: first, to ponder its sad ecological condition and eventually, to fulfil the demands of reason through responsible action.

According to this schema, however, the very heart of the encyclical's message must be teased in the core chapters three and four. Here we are invited to intellectual, moral and spiritual conversion, ${ }^{13}$ by seeing the world through God's eyes that illuminate our own. The soul of the encyclical is precisely the recognition of the root sin that propels the ecological crisis in our times (chapter three), contrasted by a robust theo-anthropology in the fourth chapter that ponders humanity's proper role as stewards of creation. Thus, "the human roots of the ecological crisis" (chapter three) can and must be subverted through the central challenge presented by the encyclical of an "integral ecology" (chapter four). Together, the core chapters capture

12 Amoris laetitia 63.

13 B. Lonergan, Self-transcendence: intellectual, moral, religious, in: Philosophical and theological papers 1965-1980, ed. R. M. Doran and R. C. Croken, Toronto 2005, pp. 313-330. 
the complexity of the God-human relationship lived in creation that is both marred by human sin but saved in Christ. Human sin has evident effects on the entire created realm maiming the beauty divinely ordered by God. But God's salvific action restores the promise for creation's final integration and fulfilment: the eschatological new creation.

It is precisely in the third chapter, where Laudato Si ponders the manifestation of humanity's sinfulness in "the signs of the times" that we find clear references to how technology can be the double-edged sword that not only improves the human condition, ${ }^{14}$ but enslaves us in the grips of evil.

It can be said that many problems of today's world stem from the tendency, at times unconscious, to make the method and aims of science and technology an epistemological paradigm which shapes the lives of individuals and the workings of society. The effects of imposing this model on reality as a whole, human and social, are seen in the deterioration of the environment, but this is just one sign of a reductionism which affects every aspect of human and social life. We have to accept that technological products are not neutral, for they create a framework which ends up conditioning lifestyles and shaping social possibilities along the lines dictated by the interests of certain powerful groups. Decisions which may seem purely instrumental are in reality decisions about the kind of society we want to build.

The idea of promoting a different cultural paradigm and employing technology as a mere instrument is nowadays inconceivable. The technological paradigm has become so dominant that it would be difficult to do without its resources and even more difficult to utilize them without being dominated by their internal logic. It has become countercultural to choose a lifestyle whose goals are even partly independent of technology, of its costs and its power to globalize and make us all the same. Technology tends to absorb everything into its ironclad logic, and those who are surrounded with technology "know full well that it moves forward in the final analysis neither for profit nor for the well-being of the human race," that "in the most radical sense of the term power is its motive - a lordship over all." As a result, "man seizes hold of the naked elements of both nature and

14 Cf. Laudato Sì 102-103. 
human nature." ${ }^{15}$ Our capacity to make decisions, a more genuine freedom and the space for each one's alternative creativity are diminished. ${ }^{16}$

The sin manifested in the technological paradigm is precisely the "original" one of hubris first committed as an act of disobedience "in the garden" (cf. Gen 3). Adam and Eve desired to be like God, but on their terms, rather than by submitting graciously to God's ordering of our nature through his love. The same sin of hubris continues to plague humanity, and in particular through the (ab)use of our technological, creative prowess. This is evident in the narrative of the building of the tower of Babel (cf. Gen 11:1-10), but that like Adam's sin, is reversed in the descent of the Holy Spirit on all flesh at Pentecost (cf. Acts 2:1-13), enabling, once more, the possibility of new life, new communication and indeed a new human family reunited with the Father. Nevertheless, what the Holy Spirit inaugurated at Pentecost will only reach its completion in the eschaton. Thus, we must remain vigilant since until then, the abuse of techne can continue to shackle how we relate to one another and who we become.

\section{Natural law as "measure" of human flourishing}

Our ability to create artefacts, change the face of the earth and alter the way we communicate with one another can manifest both the effects of original sinfulness and its redemption in Christ. Indeed, the artefacts we create, just like the actions we perform, leave their marks of hope and despair on every aspect of our nature - "body" and "soul" - in its created environment. As the Eastern Christian tradition recognizes, techne, or our ability to create, together with pathos, the passions, are the "garments of skin" (Gen 3:21) with which God garbs Adam and Eve after the Fall to protect them under the post-lapsarian harsh conditions of "death." However, after the Christ Event, they also assist the human to receive redemption and divinization. ${ }^{17}$ To be creative through making things and altering the environment to suit

15 Quotes from Romano Guardini, Das Ende der Neuzeit (The end of the modern world), Basel 1950, pp. 63-64.

16 Laudato Si 107-108, emphasis added.

17 N. Delicata, Natural law in a digital age, "Journal of Moral Theology" 4 (2015) No. 1, p. $1-25$. 
our needs is natural to the human, to the extent that, as Fr. Walter Ong, S.J, puts it "artificiality is natural to human beings. Technology, properly interiorized, does not degrade human life, but on the contrary enhances it." ${ }^{18}$ In other words, if through technocracy we become further imprisoned in the brokenness and "death" that are the marks in the world of our sinfulness, through technology we are called to humanize the world and participate in the Holy Spirit's creative action. ${ }^{19}$

It follows, that in a world where until the eschaton, life continues to struggle with death, not just in our created milieu, but in our very hearts, we need a standard for discerning between "artificial" effects and processes that when "properly interiorized" promote human flourishing, and those that are mindlessly adopted, sometimes to the extent of thwarting human well-being. In the Christian tradition, natural law as recta ratio continues to serve as this standard, even if, its accurate reading must rely on the skills of discernment, and therefore on the virtue of prudence, perfected through the gifts of the Holy Spirit.

Nevertheless, it is still worth noting that giving prominence to natural law reasoning as "measure" of human flourishing requires justification, even in the Church. This is not just because in modernity natural law increasingly came to be construed legalistically, that is, more as fixed 'content' and therefore as unchangeable "laws," rather than the very ability and process of reasoning rightly, grounded in our God-given and God-led nature that informs prudent action. It is also because the very process of consistent right moral reasoning as prudence - the intellectual virtue assisted by the other cardinal moral virtues of temperance, courage and justice that is inherently analogical more than linearly logical - has become quite foreign to us. ${ }^{20}$ In fact, as the Instrumentum Laboris in preparation for the synods on the family showed, there is "large-scale perplexity surrounding the concept of the natural law [that] tends to affect some elements of Christian teaching on the subject of marriage and the family [especially]. [...] In a vast majority of responses and observations, the concept of natural law today turns out

18 W. J. Ong, Orality and literacy: the technologizing of the word, New York 2002, pp. 8283, emphasis added.

19 S. Bulgakov, The Bride of the Lamb, transl. B. Jakim, Grand Rapids 2002, p. 320.

20 Cf. N. Delicata, Unveiling reason: a foundation for the Church's pastoral response today, "Melita Theologica" 64 (2014) no. 2 p. 19-38. 
to be, in different cultural contexts, highly problematic, if not completely incomprehensible. The expression is understood in a variety of ways, or simply not understood at all." ${ }^{21}$

This is precisely because the classical understanding of natural law, as appropriated by the Church, relies on a teleological and holistic understanding of nature. But for these past centuries of modernity characterized by a fragmentary and mechanistic imaginary of the cosmos, we have been blinded by an instrumentalist and materialist technocratic paradigm that has habituated us to assume that our dominion over God's creation should be understood as a mere "using" (verging on the "abusing") of "resources" reduced to mere things. As Pope Francis notes in Laudato Si, the effects of technocracy have not been only individualism and consumerism, but an objectification of the created realm and of each other. As the Judeo-Christian tradition has long recognized, Adam's transgression creates a brokenness of relationality not only with God and fellow human beings, but with oneself and all of creation. These effects are nowhere as evident and tragic as when we cease to grasp rightly and holistically the integral order of God's creation and our crucial participative role in it as reasonable beings.

Yet, recovering a robust understanding of natural law as the particular mode for reasonable creatures to participate in God's eternal ordering of creation $^{22}$ would in itself serve as a corrective to the technocratic paradigm.

21 Instrumentum Laboris (2014) 20-21, http://www.vatican.va/roman_curia/synod/documents/rc_synod_doc_20140626_instrumentum-laboris-familia_en.html

22 In the Summa Theologiae Prima Secundae Pars 90, 2, Aquinas writes: "As stated above $(90,1$, ad 1), law, being a rule and measure, can be in a person in two ways: in one way, as in him that rules and measures; in another way, as in that which is ruled and measured, since a thing is ruled and measured, in so far as it partakes of the rule or measure. Wherefore, since all things subject to Divine providence are ruled and measured by the eternal law, as was stated above (article 1); it is evident that all things partake somewhat of the eternal law, in so far as, namely, from its being imprinted on them, they derive their respective inclinations to their proper acts and ends. Now among all others, the rational creature is subject to Divine providence in the most excellent way, in so far as it partakes of a share of providence, by being provident both for itself and for others. Wherefore it has a share of the Eternal Reason, whereby it has a natural inclination to its proper act and end: and this participation of the eternal law in the rational creature is called the natural law. Hence the Psalmist after saying (Psalm 4:6): 'Offer up the sacrifice of justice', as though someone asked what the works of justice are, adds: 'Many say, Who showeth us good things?' in answer to which question he says: 'The light of Thy countenance, O Lord, is signed upon us': thus implying that the light of natural reason, whereby we discern what is good and what is evil, which is the function of the 
Moreover, recovering the holistic, analogical mind-set on which such a mode of reasoning depends is not as difficult or impossible as it might seem. For there are many signs, even in digital culture, that are denying and seeking to pose a corrective to the "disenchantment" propagated by the secularism and scientism of modernity. For instance, natural science is becoming increasingly aware and awed by the ongoing mystery of "emergence" and "complexity" in the cosmos. ${ }^{23} \mathrm{~A}$ culture-wide paradoxical fascination with "spirituality" tends to retrieve an appreciation and sensibility for the beauty of the created realm, even if this often manifests itself in pantheism. Just like the Christian corrective to Stoic natural law reasoning, where Christian philosophy understands the human as free agent rather than fated, a recovery of natural law reasoning today could offer a robust discerning attitude to the emergent signs of "re-enchantment" in order to compel human moral responsibility in our times. This is, after all, the essence of natural law reasoning that transcends, but also brings together, cultures for a common global ethic. ${ }^{24}$

Nevertheless, even recovering the power of natural law reasoning is not sufficient for truly moral discernment. Aware of original sin's mark on our reason, we humbly acknowledge that we can know the signs of God's Wisdom in creation only darkly, or imperfectly. For natural law to be 'read' accurately, what the Ancients called, "the Book of Nature," we must strive not only for conversion of our sensibilities and for formation in the intellectual and moral virtues, but, more crucially, be open to receive the Holy Spirit who "perfects" our human nature, by allowing us to experience God's creation, as "gospel" with divinized eyes. ${ }^{25}$ Thus, it is as reborn in Christ that we develop true attunement to the eternal law, and therefore, it is the one transformed in Christ who bears even more resolutely the responsibility to discern how the expression of human creativity through distinct technologies "changes

natural law, is nothing else than an imprint on us of the Divine light. It is therefore evident that the natural law is nothing else than the rational creature's participation of the eternal law" (emphasis added).

23 See, for instance, S. A. Kauffman, Reinventing the sacred: a new view of science, reason, and religion, New York 2008.

24 International Theological Commission, In search of a universal ethic: a new look at the natural law (2009), http://www.vatican.va/roman_curia/congregations/cfaith/cti_documents/ rc_con_cfaith_doc_20090520_legge-naturale_en.html.

25 Cf. Laudato Si chapter 2. 
culture and anthropology" to conform to God's law that orders it to the New Creation.

This responsibility is particularly salient for technologies - from social media to biotechnology - that have decisive effects on the family, since the family is the foundational environment for human formation and well-being. Any technological effects that alter our expectations and understanding of what is natural to the human, that is, that bias our experience, understanding and action in the world - what Pope Francis terms the "dominant technocratic paradigm" - can thwart creation's inherent inclination to "fullness" of life (cf. John 1:16). Thus it is paramount that, as the Church, we promote natural law reasoning that can be an important tool to help us read the signs of the times and to discern what technological effects must be promoted to enrich human flourishing, and which must be reined in to prevent a cycle of decline.

In the Summa Theologiae Prima Secundae Partis 94, 2, where he discusses "Whether the natural law contains several precepts, or only one?" St. Thomas Aquinas first presents the fundamental principles of practical reasoning, that "good is to be done and pursued, and evil is to be avoided," on which all natural law precepts must rest. ${ }^{26} \mathrm{Next}$, St. Thomas gives us a rough sketch of the fundamental inclinations to flourishing that make us human: In man there is first of all an inclination to good in accordance with the nature which he has in common with all substances: inasmuch as every substance seeks the preservation of its own being, according to its nature: and by reason of this inclination, whatever is a means of preserving human life, and of warding off its obstacles, belongs to the natural law.

Secondly, there is in man an inclination to things that pertain to him more specially, according to that nature which he has in common with other animals: and in virtue of this inclination, those things are said to belong to the natural law, "which nature has taught to all animals" [Pandect. Just. I, tit. i], such as sexual intercourse, education of offspring and so forth.

Thirdly, there is in man an inclination to good, according to the nature of his reason, which nature is proper to him: thus man has a natural inclination

26 It is also crucial to note that for Aquinas, the first principles of practical reason are ultimately also synderesis (for some equated with "conscience"), our divine given habitual orientation to God as our ultimate end. He writes: "Synderesis' is said to be the law of our mind, because it is a habit containing the precepts of the natural law, which are the first principles of human actions." (Summa Theologiae I-II 94, 1 ad 2). 
to know the truth about God, and to live in society: and in this respect, whatever pertains to this inclination belongs to the natural law; for instance, to shun ignorance, to avoid offending those among whom one has to live, and other such things regarding the above inclination (emphasis added).

Based on his Christian theo-anthropology, Aquinas concludes that there are three fundamental inclinations to human perfection according to our being created beings (that is, always dependent on the Creator), incarnate beings and spiritual or reasonable beings. Each of these inclinations can be expressed through technological mediations that allow us to be creative and not only creatures, life giving and not only life receiving, and open to mutual relationship, even with God, who is true Spirit and Person and Persons. Thus, the challenge is precisely that through the proper appropriation of technology we humanize the world through our creativity, life giving power and in the building of a human communion in imitation of God's koinonia. Ultimately our technologizing must always be - as the Ignatian motto puts it - "for the greater glory of God."

Thus, in order to be vigilant about the challenges posed to family life in our digital context because of how the technocratic paradigm biases our understanding and actual living of our natural inclinations, it is important to reflect on how contemporary technologies that we take for granted affect the family in its multiple dimensions: spiritual or relational, bodily or procreative, physical or creaturely.

To illustrate what such reflection might consider, I will offer a preliminary sketch, starting with the technological effects on our properly spiritual inclination to seeking transcendence through knowledge and relationship. It is evident that contemporary communication technologies, and most notably the Internet as meta-medium, extend our ability to live as spiritual beings, that is, as beings who grow in the ability to relate or communicate with one another, even transcending bodily limitations. As the "domestic Church," ${ }^{27}$ human relationships are the sine qua non of family life. Consequently studying the influence of technocratic biases on our desire to communicate with one another is essential to forming Christian families in a digital world.

Likewise, families by definition are the product of the natural biological urge to reproduction. Thus we cannot ignore how today's reproductive

27 Lumen Gentium 11. 
technologies alter our imaginary of what it means to become a family and how this challenges Christian married couples called to witness Christ's love for his Church.

Lastly, but perhaps more fundamentally, contemporary technologies, both medical and communicative, also implicitly alter the meaning that we give to life, existence and therefore, theologically speaking, to creatureliness. Today we exist digitally, as virtual characters, in addition to living in the 'physical' world. We create alternate 'virtual' worlds of our own in addition to that which is God-given to us. Thus, the Church needs to consider how this more subtle but, paradoxically, more drastic - shift mediated by a technocratic paradigm, also creates very serious, fundamental challenges to living the "gospel of the family," precisely because it influences our expectations of what it means to steward creation and therefore to order our common home.

\section{The Internet, truth and new relationality}

The human family is not just a biological and economic reality. It is the most foundational social and educational milieu that nurtures us to become fully human by teaching us to transcend ourselves to the other, especially the Ultimate Other. In families, we receive the essentials for our physical survival and we are trained in the skills to guarantee the livelihood of future generations. Yet more crucially, in families we are formed spiritually to become persons: men and women who desire to become loving by knowing and exchanging love. From our very conception, we belong to a family, a relational reality that by its very being imparts to the child the wisdom of relationship. These habits of relating learnt in the family - the virtues of patience, kindness, faithfulness and self-offering love - constitute our very existence as personsin-relationship.

The flourishing of our spiritual being, manifested most clearly in the expression of our natural inclination to desire truth in relationship, depends in no uncertain terms on the quality of our human relations in families. And yet, as the child grows older and is exposed to wider networks of human relationships in the neighbourhood, extended family, school and society as a whole, these patterns of relating will also inform our grasp of the truth and teach us how to act justly and mercifully towards one another. In this way, 
these social and political experiences feed back into family life, sometimes even transforming it at its core. Situations of war or natural calamities do so dramatically: they can have immediate disastrous effects on families, often changing their very constitution. But no less meaningful or long-lasting are culture and its imaginaries that have palpable effects on the family insofar as they are the very "human ecology" through which we learn to grasp the world and appreciate what is meaningful and valuable. Culture educates our sensibilities and therefore our ability to be reasonable, attest to truth and act morally. If the family, as the immediate relational circle, nurtures the child's inclination to personhood, culture is what informs the very expression of personhood among people in a particular time and space. Culture is the very context - the oikos - in which human families exist.

It is not surprising, therefore, that families are being transformed through the systemic cultural effects of new means for social communication. The Internet does not only allow us to communicate in novel ways; it becomes the very environment where human beings socialize - that is, literally create society - and in so doing, it inculcates new cultural imaginaries. These cultural imaginaries can be appreciated when we ponder attentively what it is that we do when we are online as well as the kind of language that we use to describe our novel experiences. ${ }^{28}$

Most fundamentally, the Internet is a network of machines that exchange data rapidly and effectively. The machines themselves can transmit any bit of information, but precisely because of our inherent human desire to communicate with the other, through social media in particular, we have tended to emphasize personal interaction. Whether through social networking sites, multi-user online games or online collaborative endeavours, the Internet allows us to exchange our voice, thoughts and memories, not only instantaneously, but, notwithstanding the seeming fleetingness of online interaction, permanently; and not only with our immediate social circle, but with anyone who, like us, has access to a networked machine. That 'other', known or unknown, can be anywhere and can listen to me anytime, which implies that any limits to my ability to communicate with another imposed by my condition as an embodied being are now annihilated. I no longer need

28 This is the methodology promoted in: A. Spadaro, Cybertheology: thinking Christianity in the era of the Internet, New York 2014. 
to be physically present to see the other face-to-face and converse in real time. I no longer need to be in the same location to participate in another's activity or to share a task with them. I no longer need to rely on our shared memory to access knowledge we have created together. Just like spiritual beings who transcend time and space, I - or at least my digital footprint becomes seemingly omnipresent and eternal as it acquires an existence even independent of me.

What is more, online I can enjoy multiple interactions simultaneously: whether I am consuming content at the same time that I am texting, playing or engaged in other experiences, the implicit message is that I can play multiple roles - be multiple selves - simultaneously. What is more, I am the one who chooses such interactions: at any point, I can choose to withdraw and to establish new connections. My new multiple selves are, after all, completely ephemeral and ethereal. They exist and not-exist at the click of a button or the swipe on a screen.

These new modes of relating by exchanging our thoughts, hopes, dreams, memories -everything we aspire to be that now appears possible because our online interactions seem unbound by physical limitations - recast our very sense of self, and of course, of the expectations for our face-to-face relating in physical spaces. This is true not just in the social, political sphere, but in intimate family relating as well.

Just as online I can choose to associate with whoever I want, and indeed algorithms make sure that my social circle just fits my interests, effectively constricting rather than opening my worldview, so in face-to-face physical interaction I will have less patience and tolerance for anything or anyone who challenges me to consider another point of view, or who just seems to be different. The European-wide resistance to the challenges posed by migration can be interpreted through these lens. While in theory the World Wide Web brings the whole world at our fingertips, in practice, it constricts the immensity of possible choices to mere personal preference. At its extreme, online I will merely seek images of myself to affirm my (fragile) sense of self. Such self-referentiality and narcissism is not just an expression of my fear of the other, but it will also manifest itself in intolerance, even hatred, of the other. In the political sphere this tendency translates to new waves of nationalism, xenophobia, prejudice, religious (or secular) fundamentalism. Instead of reaching out to the other, in the cacophony of different voices that 
cry for my attention in this brave new world of ubiquitous connectivity and pervasive proximity, I am threatened by otherness: their very presence casts doubt on the veracity of the bubble of 'order' that I have carved for myself (or that has been carved for me through algorithms that interpret my patterns of behaviour).

In the family however, the effects can be more devastating. The traditional distinction in the polis between the household and the political realm, what in modernity is reconceived as the private in distinction to the public sphere, ${ }^{29}$ is once more annihilated. It is as if human relating is today being reconfigured in accordance with the much older tribal, even nomadic patterns of relationship, where society itself consisted mostly of the family as blood relations and their immediate extensions (the extended family). Thus, in our context, whatever belonged to the private realm - intimacy, closeness, familiarity - is extended to wider circles, while what came to belong to the public realm - education, economic production etc. - is being reclaimed by the family (for instance, private schooling, self-sustainable homes etc.).

More peculiar, however, is the assumption that we have inherited from modernity and that we continue augmenting in a postmodern age: an individualist attitude where we assume the right to choose whom we desire to relate to, since we consider ourselves, as inherently self-creating first, rather than as persons in mutually self-offering relationships. Thus, today's "tribes," just like the Internet itself, are fundamentally grounded in personal choice. I am not born in a tribe to which I will always belong by ties of blood and mutual care, affection and loyalty. I create my own tribe to suit my needs and will recreate it when, if and as many times as I desire. ${ }^{30}$

Our experience of family living can become equally fluid: the temptation can be that family becomes whomever I consider to be my family at this point in time. Marital bonds, even blood relations, can lose their permanent, or even intrinsic, significance. Family is reduced to whom I choose to be intimate with, whom I desire to share my life with - at least at this point in time. Precisely because culture is ephemeral, our living becomes equally ephemeral, as we lose a sense of rootedness in a personal, that is, a "mutually-self-mediated,"

29 Ch. Taylor, Modern social imaginaries, Durham 2004, p. 101-108.

30 Cf. N. Delicata, Towards a Trinitarian theology of friendship in the global village, in: René Girard and creative mimesis, eds. V. N. Redekop, Th. Ryba, Plymouth 2014, pp. 97-116. 
identity. ${ }^{31}$ It is paradoxical that the moment that through our technological mediations we can conquer space and time to be all together in the immediacy of a digital augmented reality, we can also become lost, through eradicating the very intimate grounding for our personal development, that is, the family.

Thus, one can discern that if the inherent desire for communion evident in our communication technologies is a sign of our desire for flourishing, its faltering through self-referentiality as effect of a crisis of identity, is the mark of sin. The challenge for the Christian is precisely to become a "neighbour" online as well as in physical spaces. ${ }^{32}$ More crucially, Christian families have the added responsibility of revealing neighbourliness not just as individuals, but precisely in their domesticity - the unity that characterizes them as bonded to each other in physical space and through time - that best evokes the ideal of human communion. As Pope Francis teaches evocatively in his 2015 World Communications Day Message: “The family [...] is an environment in which we learn to communicate in an experience of closeness, a setting where communication takes place, a 'communicating community'. The family is a community which provides help, which celebrates life and is fruitful. Once we realize this, we will once more be able to see how the family continues to be a rich human resource, as opposed to a problem or an institution in crisis. [...] Families at their best actively communicate by their witness the beauty and the richness of the relationship between man and woman, and between parents and children. We are not fighting to defend the past. Rather, with patience and trust, we are working to build a better future for the world in which we live." ${ }^{33}$

\section{Reproductive technologies and the (re)birth of the family}

A possible crisis of identity has repercussions even for the generative, and not just relational, aspect of family living. Just like in a tribal age, where

31 Communication and Lonergan: common ground for forging the New Age, eds. Th. J. Farrell, P. A. Soukup, Kansas City 1993, p. 271.

32 World Communications Day Message 2014, https://w2.vatican.va/content/francesco/en/ messages/communications/documents/papa-francesco_20140124_messaggio-comunicazionisociali.html. Pope Francis writes: "Communication is really about realizing that we are all human beings, children of God. I like seeing this power of communication as 'neighbourliness."

33 World Communications Day Message 2015, https://w2.vatican.va/content/francesco/en/ messages/communications/documents/papa-francesco_20150123_messaggio-comunicazionisociali.html. 
children were a sign of the tribe's prosperity guaranteeing its future, our tendency today can be to consider children as an extension of the self, as our chosen "life project," more than as legitimate individuals in their own right (as per the modern mind-set). The difference between the age-old tribal mind-set and our own however, is that, just like anything else in a digital age, not only do I seek to create my own offspring (sometimes as an image of myself), but the very sense of parenthood becomes increasingly ephemeral. On the one hand, I no longer need to reproduce to shower a "child-like other" with my affection. Pets, even electronic "companions," or my career and personal interests, can be enough to project natural parental inclinations. Childlessness, just like parenthood, becomes a culturally acceptable personal choice, especially since it ties me even less to other future experiences, I might desire to explore for myself. At the same time, if I desire a child, the assumption becomes that technological mediation transforms my mere desire to a "right."

Parenthood as a choice more than a natural and expected consequence of marriage is perhaps the most obvious effect of reproductive technologies on family life. This is because, whether in the form of contraception, or of assisting and enabling conception, or in the medical and technical expertise that accompanies the gestation of the embryo and foetus, reproductive technologies enhance - in some respects, even take over - control over human fertility. Pregnancy ceases to be an almost miraculous event in the family's life, and instead becomes a series of biological happenings that are prodded, directed or altered technically at will.

Yet, with increased technical control over human reproduction, there is also the temptation to instrumentalize the process of how a human being comes to life and to objectify the very network of persons involved, that is the family itself. These signs are nowhere as evident as in the effects - intended or not - of the quintessential reproductive technology, in vitro fertilization (IVF).

As a technology, in vitro fertilization is unique even when compared to other technologies that assist human reproduction, for it does not merely assist the natural process of conception through which a human being is created, but it itself creates a human being. Even if, until further technological development, the embryo produced still requires a human uterus for their gestation until a viable birth, nonetheless IVF glaringly reveals how technology can take over completely the process of creating a new human life. Indeed, because as a technology, IVF is so powerful - the human can make others like 
himself or herself using technical means and not just through a natural act over which a couple has limited control - the danger that we become awed by the technical possibilities and blinded by our own technical prowess is even graver. Technology no longer just serves the best interests of the human being, but it could end up dictating its own "paradigm" or logic to human life, and to family life especially.

In fact, the bias of the dominant technocratic paradigm in relation to human reproduction is most evident past the tipping point when IVF ceases to be used merely medically, that is, to mimic through the use of human artefacts and skills what would have happened naturally had there been no medical issues preventing a man and woman in a stable relationship from conceiving a child and becoming parents. Instead, it starts being used to achieve ends that, not only would have been impossible until a few years ago, but even unthinkable. The very choice of parenthood becomes conditioned not, first and foremost, by the relational milieu of the couple, but by what is technically possible: whether that technical procedure aims to conceive a child without a father, to enable pregnancy after menopause, to gestate a child that is not genetically one's own, to "design" a child with specific genetic characteristics - or anything else that is technically achievable even if humanly (and therefore morally) questionable. As the technique becomes technocratic, culture itself enters a realm where just as we (often mindlessly) experiment with any new technology to explore what new products could be made or used, so reproductive technology becomes the means for social experimentation, and indeed for re-inventing the rules of human relationality. As it becomes increasingly assumed that it is sperm that impregnates a woman and not the father of her children; as we come to take it for granted that a uterus gestates a child and not his or her mother; the very meaning of parenthood, and therefore of the family, is compromised. In the process, the family as the quintessential embodied and spiritual acme of human personal flourishing is stultified too.

The Roman Catholic Church's teaching on the unity of the marital and reproductive act must be understood in this light of the challenge of technocracy to the family. That conception and gestation happen naturally in a woman's body through the loving act of her spouse has not only biological significance, but profound moral and spiritual meaning, because it reflects the proper personalist nature of the human being created 
imago Dei. ${ }^{34}$ Nature teaches us that a human being is, from the moment of conception, created in relationship with the other who properly becomes his or her mother. The mother herself is bonded to a man who fathers her child. Thus, if the relationship with the mother must be understood as the first human experience of relating with another, that relationship in utero assumes the loving relational milieu of the mother accompanied by her husband. Throughout pregnancy, mother and child interact with one another and are attuned to one another. Yet, the mother is also the medium for the growing child's interaction with the world. Not only does the child share the same sustenance that keeps them alive, but he/she experiences the mother's emotional states and, through her body, gets to experience the first sounds, tastes and light from the world. Those first experiences are infinitely enriched through the presence of the father who shares in the mother's life, as together they are reborn as family. Similarly, the mother is attuned to the child's daily rhythms of sleeping, waking and moving as, with the support of her social circle, chief of which is her husband, she adjusts her daily activity to suit the needs of the growing child. In this sense, pregnancy is a time when, notwithstanding the embryo's complete dependence on the mother, the newly created family, experience each other as persons bonded in the most intimate of human relationships.

This is why the technical manipulation of the parent-offspring relationship risks not mere objectification and commodification, but potentially also dehumanization. In fact, when reproductive technologies are pushed to their extreme, they make redundant an essential element of our creaturely reality: human sexuality itself. Insofar as technology, rather than human gendered bodies, becomes the mediator to human procreation, maleness and femaleness, motherhood and fatherhood become empty of real signification. In extracting human genetic material from its properly personalist 'human' milieu - not just from genetically human gametes and gonads, but from the ecology of human sexual-affective-social behaviour traditionally symbolized by marital and family life - effectively the technologies that sought to enhance human fertility end up making redundant natural procreation itself.

34 Cf. N. Delicata, On divine-humanity: Sergius Bulgakov's personalist theology as foundation for the Christian life, "Logos: Journal of Eastern Christian Studies" 55 (2014) No. 3-4, pp. 391-424. 
This is perhaps the main reason why the socio-cultural assumptions behind what it means to be a family are in such a radical flux today. If the Industrial Revolution emptied the family of its central economic role, if secularity robbed the family of its public and educational role, the sexual revolution has transferred the family's reproductive role to the medical establishment. As the relational, affective dimension of family life is disconnected from the reproductive dimension, 'family' is reduced to whoever (or whatever) fulfils my affective needs. The reproductive crisis is thus also a spiritual crisis - and for that reason, a profound anthropological crisis.

Yet, at the same time, it continues to express our inherent desire to give our very self to the vulnerable other. The very desire for parenthood, even when disordered, reveals the spiritual hunger for self-offering, and indeed, our trust and hope for a better life. Nurturing that sense of hope, but ordering it to trust in the true "Lord and Giver of Life," is precisely the challenge that marks our times of rapid biotechnological development that redefines our sense of creaturehood.

\section{Digitality, body and spirit}

It is a most telling "sign of the times" that the obsolescence of man and woman as reproductive agents retrieves two dormant archetypes from our not too distant past: the seed as source of life and the soil as incubator of life. The (malleable) genetic code as essential information and the uterus/ incubator as the medium for its embodiment redefine what in the West has culturally been symbolized as 'male' - that is, the logos that gives form - and 'female,' the matter in which logos manifests its form. But, through the rise of biotechnology, logos is now techne-logos, the medical establishment fathering the new human; and matter is, for all intends and purposes, mere matter, which, as Magna Carta for the knowledge age puts it, can be "overthrown." 35

This "overthrow" of matter is perhaps the most paradoxical sign of the birth of digital culture. The very cybernetic movement that gave birth to

35 E. Dyson, G. Gilder, G. Keyworth, A. Toffler, Cyberspace and the American dream: a Magna Carta for the knowledge age. Future insight, Washington 1994, http://www.pff.org/ issues-pubs/futureinsights/fil.2magnacarta.html (01.09.2016). 
digital technology gives absolute priority to "information," the new logos, radically separating it, and indeed distilling it as "code" from its material substratum. ${ }^{36}$ The phenomenon of digitality and the cult of information make matter seem redundant because the material substrata over which information is read or written, are now perceived as being interchangeable. ${ }^{37}$ Just as we come to believe that an electronic or hardcover version of the same content is the same 'book', so we come to think that it is the same "me," whether interacting in person - that is, when physically present - or online. Here, it becomes evident that properly human information is itself separated into two realms: the genetic code that writes the body, and human consciousness increasingly 'written' in the ethereal, but paradoxically permanent, digital code.

And yet, the unsustainability of a ghost-like existence is nowhere more evident than in how even in digitality, matter reclaims us to itself. The more our online friendships develop, the more we desire to take that relationship a step further and meet "in person" even while continuing the relationship in cyberspace. The more time we spend experiencing the world through screens, the more we are nostalgic for the raw beauty of the Earth and to be re-tuned to more physical, natural rhythms of life. Still, between the possible dizzying extremes of spiritual Gnosticism and materialism, a new experience of augmented reality is emerging. As our environment becomes seamlessly intertwined with the digital realm, as digital information permeates all physicality, so the very distinction between body and "spirit," matter and "energy," physical and digital starts to disappear.

Yet, this very malleability and fluctuating experience of the relationship between matter and spirit, where, on the one hand, matter is seemingly imbued with human-like intelligence at the same time that human consciousness is potentially disconnected from corporality, raises profound anthropological questions. These centre not just on how we come to understand ourselves, possibly re-interpreting the Christian attestation that we are embodied spirits, or our finality, that is, the Christian hope of bodily resurrection, but also in the way we relate to our environment as digitized reality. The experience can be

36 Cf. J. Gleick, The information: a history, a theory, a flood, New York 2011.

37 N. Delicata, 'The talk he never gave': reflections on Marshall McLuhan's 1979 talk 'Discarnate man and the incarnate Church', "Ultimate Reality and Meaning: Interdisciplinary Studies in the Philosophy of Understanding" 34 (2015) No. 3-4, pp. 231-256. 
of wonder and awe as we rediscover God's order as mediated through digital technology and we rightly submit to it. But it can also become a manifestation of hubris, where we imprudently "play God," losing any sense of justice, temperance or resilience in the face of suffering that is the inevitable mark of human sinfulness on the create realm.

At this moment of impasse, where we are reconfiguring the experience of time and space, the meaning of life and death, even renegotiating a global social and political community, there are also inevitable and poignant implications for the family as the quintessential human ecology. How do families adapt to rapid technological shifts and redefinitions of how to relate to one another and live responsively? How do they form their children for social challenges and economic realities that do not even exist yet? How does one strike a balance between the multiple, parallel realities that compel attention? How do we redefine togetherness and aloneness, love, commitment and fidelity ${ }^{38}$ Discerning the most fitting answers in a rapidly changing landscape is precisely why the "gospel of the family" must be first and foremost conceived as a "human ecology," that is, as always open to development precisely through its discerning attitude that is attuned to the presence of the Holy Spirit silently recreating the world in our midst.

7. The gospel of the family in digital culture: The hope for a new Paideia tou Kyriou

Digital technologies are recreating our culture through new opportunities for humanization, but also new dangers for a dominant technocratic paradigm to thwart the inherent integral relationality of all things grounded in God. As these new cultural assumptions become our social imaginaries, the role of the "gospel of the family" increasingly becomes that of inviting to conversion: to embrace not a technocratically-biased anthropology, but a robust and fully revealed in Christ theo-anthropology that inspires authentic human, integral flourishing. This is the fundamental challenge for a true Christian formation in our days.

38 Cf. Sh. Turkle, Alone together: why we expect more from technology and less from each other, New York 2012. 
As righteous action and creativity, and therefore authentic human flourishing, is "measured" through natural law reasoning, so natural law itself recovers its inherently pedagogical intent. Natural law not only teaches us to become more virtuous through following its precepts, but the very practice of right reasoning helps us to become more fully human. The more we become adept at reading the "signs" of our recreated milieu truthfully, that is, reading the book of God's creation, the more we are enabled to act wisely and therefore to become true "artisans of their destiny" 39 through "tending" creation (cf. Gen 2:15).

This gradual formation is precisely what Pope Francis intends with his pedagogical metaphor, "time is greater than space," first presented in Evangelii Gaudium (222-225), and then utilized as the foundation for the pedagogical approach in the Church's ministry to families, even in Amoris Laetitia. ${ }^{40}$ As Pope Francis writes: "A constant tension exists between fullness and limitation. Fullness evokes the desire for complete possession, while limitation is a wall set before us. Broadly speaking, 'time' has to do with fullness as an expression of the horizon which constantly opens before us, while each individual moment has to do with limitation as an expression of enclosure. People live poised between each individual moment and the greater, brighter horizon of the utopian future as the final cause which draws us to itself. Here we see a first principle for progress in building a people: time is greater than space. This principle enables us to work slowly but surely, without being obsessed with immediate results. It helps us patiently to endure difficult and adverse situations, or inevitable changes in our plans. It invites us to accept the tension between fullness and limitation, and to

39 Populorum Progressio 65.

40 In Amoris Laetitia 3, Pope Francis applies this principle to the process of inculturating the Gospel and the Church's family ministry: "Since 'time is greater than space,' I would make it clear that not all discussions of doctrinal, moral or pastoral issues need to be settled by interventions of the magisterium. Unity of teaching and practice is certainly necessary in the Church, but this does not preclude various ways of interpreting some aspects of that teaching or drawing certain consequences from it. This will always be the case as the Spirit guides us towards the entire truth (cf. Jn 16:13), until he leads us fully into the mystery of Christ and enables us to see all things as he does. Each country or region, moreover, can seek solutions better suited to its culture and sensitive to its traditions and local needs. For 'cultures are in fact quite diverse and every general principle [...] needs to be inculturated, if it is to be respected and applied," https://w2.vatican.va/content/dam/francesco/pdf/apost_exhortations/ documents/papa-francesco_esortazione-ap_20160319_amoris-laetitia_en.pdf. 
give a priority to time. [...] Giving priority to time means being concerned about initiating processes rather than possessing spaces. Time governs spaces, illumines them and makes them links in a constantly expanding chain, with no possibility of return. What we need, then, is to give priority to actions which generate new processes in society and engage other persons and groups who can develop them to the point where they bear fruit in significant historical events. Without anxiety, but with clear convictions and tenacity" (emphasis added). ${ }^{41}$

Through a process of discernment grounded in the Ignatian mottos, of "finding God in all things" - including the most tainted - and of always acting "for the greater glory of God" - even in the most difficult and ambiguous circumstances - the pivotal key becomes the ability to grasp rightly, understand fully and judge accurately the whole situation, not just in its present context, but also in its future possibilities, in order to "sow seeds" that allow the God-desired flourishing that is possible in that particular ecology to "take root" and grow. This is precisely how natural law reasoning allows us to simultaneously grasp the salient features of the situation and how it "measures" in relation to our natural inclinations to flourishing, always urging us forward to a deeper relationship with God who, in the power of the Holy Spirit, transforms us to become his "friends." 42

At the same time, as the Christian family embodies God's desire for humanity by becoming a "domestic Church," the cell that allows the body of Christ to be revealed in the world, it also becomes a mark of contradiction in digital culture for conversion from biased cultural assumptions to embracing a model of righteous living. The marital bond continues to reflect the beauty of humanity in its properly gendered diversity, just as the mutual self-offering in body and soul, is not only a sacrament of God's love, but indeed, also of his creative, generative kenosis. In its bonds of love, in its work to maintain the household, in being the proper ecology to sustain the birth and nurturing of children, the family corrects the narcissism and self-referentiality that can characterize our online interaction, the manipulation of life that can be the dark underside of biotechnology and the hubris of "playing God" that is the ongoing temptation of our powerful technologies. The Christian family is

41 Evangelii Gaudium 222-223.

42 Summa Theologiae II-II 23.1. 
indeed properly "the gospel" - the good news in revealing the "already" of Christ's salvation, even in a complicated digital context that remains burdened by $\sin$.

\section{Bibliography}

Bulgakov S., The Bride of the Lamb, transl. B. Jakim, Grand Rapids 2002.

Communication and Lonergan: common ground for forging the New Age, eds. Th. J. Farrell, P. A. Soukup, Kansas City 1993.

Delicata N., 'The talk he never gave': reflections on Marshall McLuhan's 1979 talk 'Discarnate man and the incarnate Church,' "Ultimate Reality and Meaning: Interdisciplinary Studies in the Philosophy of Understanding" 34 (2015) No. 3-4, pp. 231-256.

Delicata N., Natural law in a digital age, "Journal of Moral Theology" 4 (2015) No. 1, pp. 1-25.

Delicata N., On divine-humanity: Sergius Bulgakov's personalist theology as foundation for the Christian life, "Logos: Journal of Eastern Christian Studies" 55 (2014) No. 3-4, pp. 391-424.

Delicata N., Towards a Trinitarian theology of friendship in the global village, in: René Girard and creative mimesis, eds. V. N. Redekop, Th. Ryba, Plymouth 2014, pp. 97-116.

Delicata N., Unveiling reason: a foundation for the Church's pastoral response today, "Melita Theologica" 64 (2014) No. 2, pp. 19-38.

Dyson E., Gilder G., Keyworth G., Toffler A., Cyberspace and the American dream: a Magna Carta for the knowledge age. Future insight, Washington 1994, http:// www.pff.org/issues-pubs/futureinsights/fil.2magnacarta.html (01.09.2016).

Gleick J., The information: a history, a theory, a flood, New York 2011.

International Theological Commission, In search of a universal ethic: a new look at the natural law (2009), http://www.vatican.va/roman_curia/congregations/ cfaith/cti_documents/rc_con_cfaith_doc_20090520_legge-naturale_en.html.

Jones B., 'Securing the rational foundations of human living': The pedagogical nature of human law in St. Thomas Aquinas, "New Blackfriars" 96 (2015) No. 1065, pp. 602-620.

Kauffman S., Reinventing the sacred: a new view of science, reason, and religion, New York 2008. 
Lonergan B., Philosophical and theological papers 1965-1980, eds. R. M. Doran, R. C. Croken, Toronto 2005.

McLuhan M., Understanding media: the extensions of man, Toronto 1964.

Ong W. J., Orality and literacy: the technologizing of the word, New York 2002. Spadaro A., Cybertheology: thinking Christianity in the era of the Internet, New York 2014.

Taylor C., Modern social imaginaries, Durham 2004.

Turkle S., Alone together: why we expect more from technology and less from each other, New York 2012. 